\title{
CAMINHOS E DILEMAS DA EDUCAÇÃO SUPERIOR NA ERA DO DIGITAL
}

\author{
António M. Magalhães ${ }^{1}$
}

\begin{abstract}
RESUMO: A diluição da matriz moderna da educação superior nos atuais contextos socioeconómicos tem vindo a traduzir-se na hegemonia dos discursos de mercado e na centralidade do princípio da performatividade e da relevância económica, desafiando a especificidade das Instituições de Ensino Superior. A integração das tecnologias digitais na educação e na sua governação reforça a gramática política que tem vindo a hegemonizar o campo do Ensino Superior, sendo a crise pandémica um catalisador das mudanças em curso. Pretende-se trazer para a agenda de investigação em educação a questão da especificidade das experiências educativas deste nível de educação e afastar o debate da dicotomia simplista entre a celebração das tecnologias e da digitalização da educação e a tecnofobia.
\end{abstract}

Palavras-chave: Educação superior. Modernidade. Ideia de universidade. Instituições de Ensino Superior. Performatividade.

\section{PATHS AND DILEMMAS OF HIGHER EDUCATION IN THE DIGITAL AGE}

\begin{abstract}
The dilution of the modern matrix of higher education in the current socio-economic contexts has been reflected on the hegemony of market discourses and on the centrality of the principle of performativity and economic relevance, challenging the specificity of higher education institutions. The integration of digital technologies in education and its governance reinforces the political grammar that has been hegemonizing the field of higher education, being the pandemic crisis a catalyst for the changes underway. The goal is to bring to the research agenda in education the issue of the specificity of the educational experiences at this level of education and to move the debate away from the simplistic dichotomy between the celebration of technologies and digitization of education and the technophobia.
\end{abstract}

Keywords: Higher education. Modernity. Idea of university. Higher education institutions. Performativity.

Este trabalho foi financiado por fundos nacionais através da FCT - Fundação para a Ciência e a Tecnologia, I.P., no âmbito do projeto UIDB/00757/2020

1.Universidade do Porto - Faculdade de Psicologia e Ciências da Educação - Departamento de Ciências da Educação - Porto, Portugal/Centro de Investigação de Políticas do Ensino Superior - Matosinhos, Portugal. E-mail: antonio@fpce.up.pt

Editor de Seção: Licínio C. Lima 


\title{
CAMIÑOS Y DILEMAS DE LA EDUCACIÓN SUPERIOR EN LA ERA DIGITAL
}

\begin{abstract}
RESUMEN: La dilución de la matriz moderna de la educación superior en los contextos socioeconómicos actuales se ha reflejado en la hegemonía de los discursos de mercado, y en la centralidad del principio de performatividad y de la relevancia económica, desafiando la especificidad de las instituciones de educación superior. La integración de las tecnologías de digitalización en la educación y su gobernanza refuerza la gramática política que ha estado hegemonizando el campo de la educación superior, siendo la crisis pandémica un catalizador de cambios en curso. La intención es llevar a la agenda de investigación en educación la cuestión de la especificidad de las experiencias educativas en este nivel educativo y sacar el debate de la dicotomía simplista entre la celebración de las tecnologías y de la digitalización de la educación y tecnofobia.
\end{abstract}

Palabras-clave: Educación superior. Modernidad. Idea de universidad. Instituciones de educación superior. Performatividad.

\section{Introdução}

s estudos sobre a educação superior têm vindo a concentrar-se sobretudo na sua dimensão institucional, nas suas transformações organizacionais e na governação e gestão dos sistemas e das instituições e menos, como enfatizam Peters e Barnett, no conceito de educação superior:

[...] os sistemas universitários proliferaram abundantemente e universidades foram estabelecidas e desenvolvidas com pouca consciência de que existe uma consolidada literatura que pode informar o debate. Há um apagão em relação a essa literatura. A universidade enquanto instituição presta pouca atenção à universidade enquanto ideia (2018, p. xiii-xiv).

Esta secundarização da investigação sobre a ideia de universidade estende-se à escassez de reflexão sobre o que é o "superior" da educação superior. As Instituições de Ensino Superior, em geral, e as universidades, em particular, têm concentrado os seus esforços na adaptação e na articulação das suas estruturas e dos seus processos à fluidez das transformações do seu ambiente organizacional. De facto, na área dos estudos sobre o Ensino Superior, tem proliferado a investigação sobre as suas governação e gestão, sobre a avaliação da sua qualidade, sobre os instrumentos de accountability, sobre as métricas do desempenho dos académicos, dos investigadores e do pessoal de apoio à gestão, sobre a internacionalização como estratégia de desenvolvimento do setor e sobre a empregabilidade dos seus graduados. A dimensão educativa, quando assume centralidade é, o mais das vezes, para identificar o conjunto "relevante" das competências e das habilidades que, como resultados da aprendizagem (learning outcomes), tornem empregáveis os diplomados por este nível educativo.

É compreensível que, por exemplo, a Organização para a Cooperação e Desenvolvimento Económico (OCDE), dada a natureza da instituição, enfatize que " $[\mathrm{u}] \mathrm{m}$ dos principais objetivos do Ensino Superior é proporcionar aos seus graduados as competências necessárias para terem sucesso no mercado de trabalho" (OECD, 2017, p. 9). Ou que o Banco Mundial sublinhe que, para além de educar os estudantes, e havendo uma cada vez maior procura deste nível de educação, também "há uma maior procura entre os empregadores 
de trabalhadores qualificados e profissionais, e atribuída uma importância cada vez maior nas economias modernas à investigação e ao desenvolvimento, a fim de aumentar a competitividade" (WORLD BANK, 2017, p. ix). O que surpreende, como sugerem Peters e Barnett (2018), é que, por parte dos investigadores em educação, a concetualização da especificidade da dimensão educativa do Ensino Superior e das suas instituições tenha vindo a ser negligenciada.

Cumpre, de facto, relevar a especificidade da educação superior e das instituições onde esta se desenvolve. Neste sentido, é importante, a partir da herança moderna da conceção da universidade e da formação a que ela visava, identificar e cartografar os seus caminhos - não só os meramente possíveis, mas, sobretudo, os desejáveis - num momento em que a ligação entre a universidade e a razão enfraqueceu e outras narrativas públicas sobre a sua natureza emergem, como a da universidade empreendedora, ou de outras fundadas na sua utilidade económica e social. Ligadas à crescente hegemonia destas narrativas estão as transformações das experiências educativas dos(as) estudantes e dos professores(as), designadamente através das tecnologias de informação e comunicação (TIC), da digitalização da educação, e das suas governação e gestão.

Este artigo procura, assim, contribuir para a discussão acerca da especificidade educativa da universidade e da educação superior, incidindo sobre os efeitos conjugados da centralidade atribuída ao Ensino Superior para o desenvolvimento económico e das crescentes tecnologização e digitalização do ensinar e do aprender. Esta última, enquanto transformação dos materiais, métodos e técnicas de apoio aos processos e estruturas educativos em linguagem digital, é considerada já por alguns um ponto de viragem na história da educação (MACHEKHINA, 2017).

Na confluência da perda de ligação com a matriz moderna da educação superior, da tecnologização fundada no digital dos processos e estruturas de investigação, educação e governação das instituições, a crise associada à pandemia provocada pela Covid-19 é convocada como um analisador da importância e da urgência desta discussão para a identificação da especificidade das experiências educativas da educação superior e, desde logo, para as agendas políticas e educativas.

\section{A Diluição da Matriz Moderna da Educação Superior}

Na Europa, segundo Gellert (1993), a matriz moderna da educação superior desenvolveu-se com base em três modelos: o do Conhecimento, correspondente à ideia humboldtiana de universidade (o "modelo da investigação"); o Profissional, ligado às grandes écoles francesas (o "modelo da formação") e concentrado, sobretudo, na produção de quadros para o aparelho de estado; e o da Personalidade, ligado à tradição de Oxbridge, que assenta na ideia de formação dos indivíduos através de uma educação liberal (o "modelo da personalidade") (GELLERT, 1993). Todavia, como instituições científicas, profissionais ou culturais, estes três modelos estavam narrativamente fundados na matriz da modernidade, compartilhando a celebração da razão, do conhecimento e da crítica como base dos processos educativos. Compartilhavam, também, o elitismo social, que ainda hoje faz o seu caminho nos sistemas e Instituições de Ensino Superior. A matriz moderna da educação superior fornecia uma ampla base de consenso que, hoje, está a fragmentar-se, num processo dominado por um discurso que, potencialmente, veicula uma nova, ou novas, identidade(s) da educação superior e das suas instituições (MAGALHÃES, 2004; 2006). Este discurso tem vindo a assumir visibilidade nas narrativas empreendedoras/empresarialistas e de mercado na educação superior que, ao subsumirem a educação superior ao princípio da perfomatividade e da relevância económica, potenciam a diluição da especificidade das organizações a ela dedicadas como instituições autónomas de ensino, investigação e serviço à sociedade. A formação de indivíduos, cidadãos e profissionais, principalmente aqueles que apoiavam o 
aparelho do Estado, estava estritamente ligada à ideia de educação superior. Ensinar, aprender, estudantes, professores, aulas, campi etc. estavam unidos, quer pela narrativa fundada no potencial emancipador do conhecimento moderno, quer pelo projeto de consolidação do Estado-Nação; ou seja, o conhecimento deveria ser procurado sem interferências, como condição para a afirmação da cultura e da ciência "nacionais" (MAGALHÃES, 2004). Professores e estudantes reuniam-se em anfiteatros e laboratórios e viviam em campi no âmbito de uma relação educacional mediada pela função "iluminadora" do conhecimento e das suas aplicações. Foi sobre estas assunções que, em parte, o mito das universidades como "torres de marfim" foi construído, obnubilando, no passe, a ligação intrínseca destas instituições ao elitismo sociológico que as foi marcando e, em muitos sentidos, continua a marcar (BARNETT, 1997).

O ideal moderno de educação pressupunha que a exposição dos(as) estudantes ao conhecimento potenciava característicasemancipatóriase transformadorasnosindivíduos, proporcionando, simultaneamente, à sociedade a formação superior de cidadãos e de trabalhadores especializados. Atualmente, a centralidade dada ao desenvolvimento de competências - definidas como a capacidade de convocar conhecimentos, experiências e atitudes para lidar com situações sociais específicas, com ênfase para os contextos laborais tem vindo a reconfigurar a educação no Ensino Superior. A investigação, por sua vez, foi removida da "torre de marfim" para o terreno de "relevância social", desafiando o papel e as funções institucionais, sobretudo das universidades. A tendência para a segmentação entre as funções de ensino e de investigação questiona a ideia moderna de educação superior, em que as instituições deveriam ensinar o que investigavam. Na verdade, o "superior" do Ensino Superior dependia precisamente da ligação entre pesquisa e ensino.

Em 1996, Cowen (1996) falava já da "atenuação" da universidade ao nível do espaço, referindo-se à sua dimensão internacional e à sua conexão com a economia; ao nível financeiro, dada a crescente clientelização dos estudantes e das suas famílias; ao nível pedagógico, pela massificação do Ensino Superior e a transformação dos(as) professores(as) em "desenhadores de instrução"; e ao nível da avaliação da qualidade, pela tendencial substituição dos académicos por técnicos especializados na formulação de juízos de valor acerca das atividades levadas a cabo nas instituições de educação superior. Esta diluição da especificidade da universidade como instituição reflete-se no que Sousa Santos (1994) designa como a tripla crise da universidade: crise de legitimidade (i. e., da falência dos objetivos coletivamente assumidos em relação à universidade); crise institucional, referente ao pôr em causa a sua especificidade organizacional; e crise de hegemonia, referente ao questionamento da exclusividade dos conhecimentos que a universidade produz e transmite.

Mesmo as fronteiras externas das instituições parecem diluir-se à medida que as funções das instituições de educação superior são cada vez mais simuladas por outras organizações, como são os casos, por exemplo, da concessão de graus, que também podem ser concedidos por empresas, ou da investigação que é realizada por laboratórios e institutos não universitários, como nos EUA, na Grã-Bretanha e na China.

A crescente ênfase na relação do Ensino Superior com o desenvolvimento económico e social e na articulação da formação superior com as necessidades do, sempre em mudança, mercado de trabalho e das reformas da governação e da gestão das instituições tem vindo a marcar o desenvolvimento e a configuração da educação superior, um pouco por todo o mundo. Instituições transnacionais, como o Banco Mundial, a UNESCO, a OCDE e a União Europeia, através dos mecanismos de soft law, têm sido, de facto, indutoras de mudanças e transformações que contribuem para transformar a face da educação superior (MAGALHÃES; VEIGA, 2013) e a relação entre massificação e democratização do Ensino Superior. Nestes desenvolvimentos, o que surge como importante foco de discussão é a educação proporcionada pelas Instituições de Ensino Superior, consubstanciada nas experiências educativas dos(as) seus(suas) estudantes.

Veja-se, por exemplo, o conteúdo da publicação de um grupo de trabalho da OCDE sobre "credenciais alternativas" (KATO; GALÁN-MUROS; WEKO, 2020). O documento - depois de sublinhar 
que, apesar do aumento do número de graduados pelo Ensino Superior nos países da OCDE, as qualificações dos seus diplomados "continuam, em média, a trazer benefícios económicos para aqueles que adquirem (esses diplomas)” (KATO; GALÁN-MUROS; WEKO, 2020) -, acrescenta que

[...] novas maneiras de adquirir e sinalizar habilidades (skills) estão a surgir e a envolver milhões de estudantes. As chamadas "credenciais alternativas" - como, por exemplo, microcredenciais, digital badges e certificados reconhecidos pela indústria - têm sido apontadas como um meio de preencher uma lacuna dos programas que as Instituições de Ensino Superior (IES) oferecem e as habilidades que as empresas procuram; como forma de aumentar a eficiência dos sistemas de Ensino Superior, oferecendo uma formação muito mais direcionada do aquela que os programas tradicionais de graduação fornecem; e como uma força de inovação, permitindo que tipos de organizações totalmente novos entrem no mercado de Ensino Superior e criem novas maneiras para as IES tradicionais chegarem a novos estudantes em todo o mundo (KATO; GALÁN-MUROS; WEKO, 2020, p. 7).

O objetivo do documento é apoiar os formuladores de políticas dos países que integram a OCDE, definindo terminologias, identificando as características das referidas credenciais e analisando o perfil de quem as atribui e de quem as recebe, bem como o modo como os empregadores e os governos as percecionam.

Menos do que saber se esta oferta de alternativas de provisão e reconhecimento de credenciais põe em causa o monopólio das Instituições de Ensino Superior na identificação e no reconhecimento dessas credenciais, parece ser importante sinalizar a injunção de que as instituições de educação superior devem reformar as experiências educativas que proporcionam aos(às) estudantes, em detrimento da questão da especificidade dessas experiências.

Gibbs, Jameson e Elwick identificam, nas políticas e nas práticas da educação superior, uma "deriva da educação como um fim em si mesmo para um imperativo de fornecer a economia” (2019, p. 4) aquilo de que ela necessita, reclamando a especificidade da educação superior e dos seus valores. De facto, a questão de saber de que modo as Instituições de Ensino Superior podem construir alternativas de ensinar e de aprender que não se reduzam ao seu value for money surge como central. Os mesmos autores são enfáticos ao sublinhar que "[é] necessário reafirmar valores académicos básicos, colocando-os num contexto moral de cuidado e de tolerância, afastando-nos muito claramente dos valores predominantes do individualismo, consumismo e interesse pessoal" (GIBBS; JAMESON; ELWICK, 2019, p. 5). É neste sentido, também, que pode ser interpretada a assunção de Giroux segundo a qual a formação de cidadãos críticos é crucial para a democracia, devendo "a universidade desempenhar um papel central na criação de culturas formativas que tornem possível a existência desses cidadãos (GIROUX, 2014, p. 210).

\section{A Tecnologização e Digitalitalização do Ensinar e do Aprender, a Governação Digital e a Educação Superior}

É neste contexto de fragmentação da matriz moderna da educação superior e da sua crescente funcionalização em relação ao campo do desenvolvimento económico que as questões levantadas pela incorporação das TIC e da digitalização dos processos e estruturas de educação, investigação e governação das instituições ganham relevância. Trata-se de discutir como esses meios e instrumentos transformam as experiências educativas, como articulam as transformações anteriormente convocadas e como afetam os processos de expansão democrática desse nível educativo. 
A configuração do ensinar e do aprender, dos seus materiais e dos seus métodos e técnicas em linguagem digital tem vindo a reconfigurar a educação, as relações educativas e as suas formas de governação. A sua importância já era visível nas prioridades assumidas nas agendas das políticas educativas europeias - e para além da Europa -, mas foi potenciada e fortalecida na sua justificação pela crise provocada pela pandemia da Covid-19. A Comissão Europeia, na sua visão para a criação de Espaço Europeu da Educação, tendo como horizonte 2025 (COMISSÃO EUROPEIA, 2017), punha em relevo, em 2017, a necessidade de colocar a melhoria da qualidade e da inclusão da educação, enfatizando o imperativo do desenvolvimento de competências digitais. Em janeiro de 2018, a Comissão adotou o primeiro Plano de Ação para a Educação Digital e definiu ações para o período 2018-2020, com o objetivo de apoiar os Estados-membros no enfrentar dos desafios e nas oportunidades decorrentes da utilização de tecnologias digitais na educação e formação (COMISSÃO EUROPEIA, 2018). Este plano concentrou-se na educação formal (escolas primárias e secundárias, o ensino e a formação profissionais e o Ensino Superior) e apontou três prioridades: aproveitar melhor a tecnologia digital para ensino e aprendizagem; desenvolver competências e habilidades digitais; e melhorar a educação através de análise mais consistente de dados e previsão.

A crise desencadeada pela pandemia da Covid-19 veio dar impulso e urgência às questões da digitalização e das competências digitais. Convocando os resultados de uma consulta pública levada a cabo entre fevereiro e setembro de 2020, a Comissão Europeia assume a necessidade de definir orientações práticas ao nível europeu, em especial para os ministérios e as instituições de educação e formação, sobre formas de implementar a aprendizagem à distância, on-line e combinada (COMISSÃO EUROPEIA, 2020a)

No que diz respeito ao Ensino Superior e à prioridade de desenvolver competências digitais, com o objetivo de criar uma plataforma europeia para o Ensino Superior, o projeto OpenU (Online Pedagogical Resources for European Universities), financiado através do Erasmus+, teve início em abril de 2019 e foi implementado por um consórcio de vinte parceiros provenientes de onze países. A próxima etapa será a criação de um hub europeu de aprendizagem on-line e combinada, mobilidade virtual e intercâmbio de boas práticas (COMISSÃO EUROPEIA, 2020b).

Em 2020, embora reconhecendo que as prioridades do Plano de Ação de 2018 haviam permanecido relevantes, a Comissão sublinhou ser necessário atualizá-las no sentido de perspetivar os seus efeitos a longo prazo, devido, em parte, aos desafios colocados pela pandemia. Assim, o Plano de Ação foi revisto e foram apontadas duas prioridades: promoção do desenvolvimento de um ecossistema de educação digital eficiente; e promoção de habilidades e competências para a transformação digital (COMISSÃO EUROPEIA, 2020b). Assim, a digitalização da educação e o desenvolvimento de competências digitais tornou-se uma questão política central na agenda da política educativa. Todavia, a digitalização da educação, em geral, e da superior, em particular, para além dos seus impactos na forma de ensinar e de aprender e na gestão do espaço e do tempo dos(as) professores(as), dos(as) estudantes e dos(as) profissionais de apoio das instituições, introduz transformações na própria conceção da educação superior. O uso da tecnologia digital deve ser visto em função do propósito da educação superior, olhando criticamente para as perspetivas das diversas partes interessadas neste processo, sobretudo para aquelas cujos discursos se vão constituindo como dominantes. O estudo destas transformações constitui, só por si, um projeto multidimensional de investigação, pois são o conhecimento e a sua natureza, forma de produção, distribuição e consumo - portanto o seu valor social e educativo - que estão em causa.

Lyotard, em A Condição Pós-moderna, em 1979, falava de duas formas de conhecimento - narrativo e científico -, sendo que, nas sociedades da informação computadorizada, o último dominaria. Nessa obra, sobre o estatuto do saber nas sociedades pós-industriais, sublinhava-se que, nesse contexto, o conhecimento se tornava numa "mercadoria informacional" (LYOTARD, 1989, p. 19-20), a "principal força de produção" 
(LYOTARD, 1989, p. 19). Nesta perspetiva, o conhecimento é uma mercadoria a circular em ambiente competitivo de mercado. A centralidade e a dominância assumidas pelo conhecimento suscetível de ser traduzido e expresso em linguagem de máquina, por um lado, e a sua mercadorização, por outro, subsomem o saber ao princípio da performatividade, isto é, à maximização dos resultados em relação aos inputs. Isto quer dizer que o conhecimento é procurado não tanto por seu valor em si, mas pelo seu valor de troca.

Desde a sua publicação, o trabalho de Lyotard desafiou e foi confrontado pelos(as) investigadores(as) em educação. Roberts (2019) respondia à questão de saber se o anúncio de Lyotard da "morte do professor" se teria cumprido, dizendo que não e que sim, porque, por um lado,

[...] continuamos a ter universidades, como espaços físicos com campus e edifícios universitários. Nesses campi há professores, que ministram aulas presenciais em salas de aula, laboratórios e anfiteatros. Os professores estão muito vivos e bem, com uma presença não apenas na vida dos estudantes, mas no mundo em geral, sendo sua experiência ainda procurada, pelo menos em alguns campi, pelos meios de comunicação social, pelos governos e pelo mundo empresarial. Professores e outros membros do corpo académico estão mais ativos do que nunca na investigação, impulsionados em parte por algumas das tendências prenunciadas pela análise de Lyotard - em particular, no surgimento de novos regimes de financiamento da investigação com base no desempenho (ROBERTS, 2019, p. 78).

Por outro lado:

[...] a morte e o morrer, num sentido simbólico, estão em toda a parte na universidade contemporânea. Essas mudanças são, em parte, um reflexo dos desenvolvimentos na educação on-line, mas também sinalizam mudanças mais profundas na forma como o poder é exercido em todo o mundo (ROBERTS, p. 78).

O autor conclui, então, que "o processo de mercantilização do conhecimento e de reconfiguração do Ensino Superior de acordo com o princípio da performatividade é um projeto incompleto [...]” (ROBERTS, 2019, p. 78). É precisamente nessa incompletude que é necessário instalar o debate.

Os modelos de ensinar e aprender veiculados pelos Massive Open Online Courses (MOOC), que, desde o final dos anos 2000, ganharam visibilidade no Ensino Superior, podem ser vistos como exemplo da marca da performatividade nos atuais contextos educativos desse nível de ensino. Em 2017, centenas de instituições, em parceria com a Coursera, a edX e a Udacity, ofereciam MOOC já a mais de 10 milhões de participantes de todas as partes do mundo (LONGSTAFF, 2017). Como diz Longstaff, "[a]través de um formato modular, on-line e com base no vídeo, os MOOC oferecem às universidades uma forma de vender os seus produtos a uma audiência global de uma forma sem precedentes, sem, ou com poucos, custos para os participantes" (LONGSTAFF, 2017, p. 314). Contudo, os MOOC têm vindo a ser questionados, não só porque as taxas de sucesso dos seus participantes andam à volta dos 13\% (HOWARTH et al., 2016, p. 75), como também porque, num sentido diferente do que seria expectável, são os indivíduos com situações económicas mais confortáveis e com níveis mais elevados de educação que, tendencialmente, procuram esses cursos (EVANS; MCINTRYE, 2016, p. 315). Ademais, os contornos da sua conceção dos processos educativos, dos seus instrumentos e das relações pedagógicas são um sinal e um possível analisador das transformações que a educação superior está a viver. Neste contexto, surge renovada a visibilidade e a importância de atores como os profissionais que traduzem as aulas gravadas em MOOC, especialistas em educação on-line e a/à distância, para não falar já das empresas e das instituições que fazem da digitalização da educação o centro da sua atividade. 
A educação e a formação têm vindo a incorporar a digitalização dos processos de ensino e aprendizagem e a reconfigurar as experiências educativas proporcionadas aos(às) estudantes nas Instituições de Ensino Superior. Professores, estudantes, espaços e tempos e as metodologias e técnicas de ensinar e de aprender estão a ser transformados pelo efeito combinado da digitalização e da pressão da performatividade, assim como pelos interesses dos diferentes atores nelas envolvidos.

Com este processo, entretecem-se formas de governação da educação que, simultaneamente, alimentam e são alimentadas pela digitalização das suas estruturas e processos, assim como os de ensinar e aprender, designadamente no Ensino Superior.

A governação dos sistemas sociais tem vindo a ser marcada pela fragmentação do controlo estatal em redes de atores e especialistas na construção e na identificação dos problemas a confrontar, influenciando a construção das agendas e tomadas de decisão. Na Europa, nos anos 1980, o modelo de controlo do Estado deu lugar ao modelo de supervisão estatal, reduzindo a interferência da administração do governo central nas decisões diárias nas instituições públicas. A assunção era que a atribuição de autonomia a essas instituições correspondia à promoção da autorregulação dos sistemas e instituições e, implicitamente, do bem público. A crítica ao modelo de controlo estatal foi aprofundada pelo discurso neoliberal, sublinhando este que a ação do Estado deveria ser limitada à garantia da ordem social, à segurança coletiva e à correção dos eventuais efeitos sociais negativos resultantes da regulação pelo mercado. Este último e os modelos organizacionais próprios das empresas foram induzidos como a forma de tornar mais eficientes e eficazes os sistemas e instituições públicos na promoção do bem público (MAGALHÃES et al., 2013). Esta mudança teve impactos na forma de governação e gestão dos sistemas e Instituições de Ensino Superior, bem como teve consequências no desenho e no conteúdo das ofertas e da educação aí desenvolvidas (p. ex., MAGALHÃES; VEIGA, 2013).

Esta gramática política de governação e gestão do sistema e das Instituições de Ensino Superior é potencialmente reforçada pela adoção de instrumentos e racionais do digital, sendo a governação digital um meio poderoso ao seu serviço. Os instrumentos de governação digital são visíveis na expansão das altamente complexas infraestruturas técnicas de recolha, armazenamento, análise e disseminação de dados aos níveis nacional e internacional. Os dados relativos à educação são um produto que resulta da confluência de redes, tecnologia e políticas que se desenvolvem para além dos sistemas de educação formal (WILLIAMSON, 2020). Se, atualmente, os desenvolvimentos das TIC são direcionados para o acesso aos vários recursos digitais de aprendizagem e para a comunicação entre estudantes, professores(as) e instituições, "há razões para crer que uma nova era ou paradigma, baseados nas TIC, está a emergir” (FEVOLDEN; TØMTE, 2015, p. 348). As Instituições de Ensino Superior e as diferentes partes interessadas no setor geram dados e atividades em rede que podem ser usados para analisar como os(as) estudantes aprendem com vistas a potenciar os seus resultados. Os sistemas de aprendizagem adaptativos, a learning analytics e os big data ganham uma centralidade na governação da educação superior ao nível dos sistemas, das instituições e das próprias relações pedagógicas.

Williamson chama a atenção para o facto de que,

[...] se a governação digital concetualiza as mudanças nas práticas do Estado - e as instituições técnicas que crescentemente co constituem o poder do Estado -, à medida que os dados digitais disponíveis para conduzir uma constante auditoria da população, a governamentalidade algorítmica regista, num sentido mais foucaultiano, como é que os algoritmos que processam os dados digitais podem ser usados para intervir e governar a vida das pessoas (2020, p. 25-26).

Este investigador apresenta o projeto e a ação da Pearson como um caso exemplar da governação digital da educação, que, de facto, não pode ser isolada da expansão da economia digital global. A empresa 
é apontada como sendo das mais bem-sucedidas no mercado da educação e um importante influenciador das políticas educativas. Em 2016, a Pearson reforçou a prioridade de ser a primeira empresa do digital pela criação de uma plataforma digital de aprendizagem, combinando, numa só arquitetura, os serviços baseados na nuvem com a análise computacional sistemática de dados ou estatísticas e com as potencialidades da máquina de aprender (WILLIAMSON, 2020). Um dos objetivos visados, sobretudo através do conhecimento proporcionado pelo desenvolvimento da inteligência artificial, é a interação direta e individualizada com os(as) estudantes "e assim dar forma à sua capacidade cognitiva em relação a fins instrumentais particulares" (WILLIAMSON, 2020, p. 38), personalizando os processos de aprendizagem.

A abordagem de Michel Foucault das técnicas de governação ganha aqui especial relevância. A "governamentalidade", ou a "conduta da conduta" (FOUCAULT, 1991), assenta no conhecimento construído pelos poderes políticos pela recolha e a análise de dados no sentido de intervir nas vidas dos indivíduos e gerir as populações. A agenda para o estudo da governação da educação requer, portanto, que, por um lado, se identifiquem as redes políticas de atores e de especialistas e, por outro, a análise das ideias e técnicas específicas para a consecução dos objetivos traçados. O modo como as políticas educativas são geradas, sob que influências e como se relacionam, nesses processos, o Estado, o setor privado, os especialistas e a sociedade civil trazem para o centro das questões de investigação em educação as técnicas que visam estabelecer discursos, novas rotinas e práticas nas instituições e nos contextos educativos. Lascoumes e Galès (2007) enfatizam, precisamente, que os instrumentos políticos são uma forma condensada de conhecimento sobre o controlo social e, porque não são neutros, produzem efeitos específicos, "que estruturam a política pública em consonância com a sua lógica própria” (LASCOUMES; GALÈS, 2007, p. 3).

No seu anúncio de uma nova condição do conhecimento e do saber, Lyotard previa que "o antigo princípio de que a aquisição do saber indissociável da formação (Bildung) do espírito, e mesmo da pessoa, cai e cairá cada vez mais em desuso" (LYOTARD, 1989, p. 18). A diluição das experiências educativas dos(as) estudantes e professores(as) no éter do www, a reconfiguração dos espaços e dos tempos de formação, a crescente transformação das competências e qualificações adquiridas na educação superior em mercadoria, num contexto em que a governação dos sistemas e das Instituições de Ensino Superior crescentemente parece assumir a performatividade como critério de valor, tornam, portanto, urgente o debate sobre o que é a educação superior, assim como o seu valor social. De facto, em última análise, com o anunciado fim da grande narrativa da modernidade e da centralidade da produção e da aquisição do conhecimento como processo de formação dos indivíduos e dos cidadãos, não são apenas as narrativas fundadoras da educação superior que estão em causa, mas a própria conceção de Ensino Superior.

\section{O Momentum Covid-19 e a Educação Superior}

A universidade tem já uma história de educação a distância e on-line, liderando, por exemplo, a educação "aberta" mesmo antes da popularização da Internet. A educação e à distância tem vindo a incorporar a digitalização dos processos de ensino e aprendizagem e, no contexto da pandemia da Covid-19, houve uma veemente utilização destas formas de ensinar e de aprender, por exemplo, no intenso recurso às aulas on-line. O Chefe da Unidade para as TIC em Educação da UNESCO, Fengchun Miao, em abril de 2020 (UNESCO, 2020), numa apresentação na instituição, enfatizou a necessidade de os decisores políticos e os líderes institucionais aproveitarem a circunstância da pandemia e as lições que daí possam ser extraídas para avançarem para a fase de planeamento do futuro da educação. No entanto, esse avanço deverá ser enraizado num debate sobre as dimensões pedagógicas que a criação e a disponibilização de infraestruturas 
e instrumentos tecnológicos por si só não podem resolver. Nessa linha, e como alerta, um estudante da Universidade de Duke fala do surgimento da "Universidade Zoom", sublinhando o caráter arbitrário dos processos e das estruturas da aprendizagem remota e o potencial desmantelamento da pedagogia na universidade (CHRAPLIWY, 2020).

A crise provocada pela pandemia constituiu um momentum para que a discussão das questões aqui tratadas ganhasse maior urgência. Em outubro de 2020, a Academic Cooperation Association (ACA) publicou um conjunto de reflexões de vários académicos e responsáveis institucionais, $O$ mundo depois da Covid (ACA, 2020). Foram aí relevados os esforços de adaptação das instituições à educação a distância, on-line e combinada. Alguns(mas) autores(as) chamaram a atenção para a impreparação dos(as) professores(as) e estudantes para lidarem com a situação criada, designadamente em relação à necessidade de desenhos mais elaborados e adequados para o desenvolvimento dos cursos e da respetiva avaliação; outros(as) para as possibilidades (desejáveis ou indesejáveis) abertas para organização e participação de eventos académicos; outros(as), para como, na recessão económica provocada pela Covid-19, a questão da empregabilidade dos graduados se torna ainda mais central; outros(as) enfatizaram o potencial decréscimo da mobilidade de estudantes, professores(as) e investigadores(as), bem como respetivas consequências financeiras; outros(as), ainda, sublinharam os desafios que estão a ser postos à governação dos sistemas e da gestão das Instituições de Ensino Superior.

Também em 2020, Michael Peters e Fazal Rizvi, na introdução de um trabalho coletivo sobre as novas possibilidades pedagógicas para as universidades, no contexto pós-Covid-19, enfatizavam que "as pedagogias digitais não são, obviamente, neutras no que diz respeito ao tipo de sociabilidade que veiculam" (PETERS et al., 2020, p. 2), apelando, também, ao repensar não apenas das possibilidades proporcionadas pelas tecnologias digitais e atividades on-line, mas das finalidades básicas da educação e do seu contributo para desenvolver sociedades mais democráticas e justas.

Do conjunto dos contributos dessas publicações, ressalta-se que a crise pandémica é um catalisador das questões e dos dilemas com que a educação superior se vem debatendo nas últimas décadas. Neste sentido, é importante cuidar para que o tão repetido ideógrafo "novo normal" não remeta mais para a "normalidade" anterior à crise do que ao que pode ser realmente novo. Por exemplo, Dirk Van Damme (2020), na publicação da ACA citada, chama a atenção para o facto de algumas universidades, nomeadamente as do Reino Unido, cujo financiamento não está protegido pelo financiamento público, estarem a ser postas em causa devido ao seu próprio "modelo de negócio", dado o decréscimo de estudantes estrangeiros. À data da escrita do seu texto, algumas universidades britânicas anunciavam mesmo que iriam assumir as aulas totalmente on-line, tendo, aliás, as reações imediatas sido, sobretudo por parte dos estudantes, muito críticas em relação a essa decisão (VAN DAMME, 2020). Procurando ver para além do tempo de crise, o autor conclui que a questão "realmente importante" é o que intrinsecamente define a experiência da universidade e cujo valor a distingue. Mesmo que a massificação da educação superior tenha alterado o modelo educacional fundado no encontro entre professores(as) e estudantes e o ideal humboldtiano de uma formação com base na investigação, muitos graduados e estudantes ainda veem nesses modos de ensinar e aprender a mais valiosa das experiências.

A crise da Covid-19 e os seus posteriores desenvolvimentos podem forçar universidades e estudantes a mudar seu quadro de referência de ensino e aprendizagem de alta qualidade; é que desenvolver novos modos de ensinar que sejam igualmente motivadores e eficazes, e ao mesmo tempo competitivos em relação a modos alternativos de oferta e certificação, vai exigir muita imaginação, criatividade e inventiva. As universidades precisam de repensar a questão do valor por dinheiro e considerar se este não é o momento de fazer os investimentos necessários 
para fazer a transição acontecer. O preço por negligenciar esse desafio agora pode ser muito alto (VAN DAMME, 2020, p. 29).

A questão é, pois, saber qual o papel que a centralidade das TIC e da crescente digitalização dos processos e materiais educativos desempenha nos desenvolvimentos que parecem conduzir à diluição da universidade herdada da modernidade e à reconfiguração das experiências educativas a ela ligadas, assim como saber em medida afeta os processos de expansão democrática desse nível educativo.

Não se trata, portanto, de negar as potenciais vantagens da migração de partes importantes do ensinar e do aprender para o mundo virtual e on-line, mas de debater como é que os curricula poderão integrar uma abordagem das experiências educativas dos(as) estudantes inclusiva, ecológica e sustentável no âmbito das interações nas redes e plataformas virtuais académicas nacionais e internacionais. A reformulação das agendas e a definição de prioridades por parte dos sistemas e Instituições de Ensino Superior com certeza integrarão as ofertas de formação virtuais e on-line, mas é importante que a relação pedagógica face a face não seja subestimada como sendo acessória no processo de formação, e que a questão da perpetuação das desigualdades no acesso e no sucesso na educação superior não seja secundarizada. De facto, como na educação em geral, os(as) estudantes do Ensino Superior provenientes de grupos sociais economicamente mais frágeis são os(as) que mais sofreram o impacto da presente crise, tornando ainda mais crítica a melhoria das condições de igualdade de acesso e permanência no Ensino Superior. Da mesma forma, continuará a ser importante o questionamento da priorização e do isolamento curricular da formação nas áreas disciplinares da ciência, da tecnologia, da engenharia e da matemática (CTEM), secundarizando a relevância das ciências sociais e humanas, das humanidades e das artes na educação superior.

No que respeita às formas de governação e de gestão das instituições, é importante que, pela crescente centralidade dos instrumentos informáticos de monitorização do desempenho das instituições, dos académicos, dos estudantes e do pessoal técnico de apoio, não seja reforçada a fragilização dos valores da liberdade de ensinar e de aprender e a autonomia académica. Nas últimas décadas, na Europa, com matizados e diferenças no ritmo de implementação, as reformas da governação e da gestão dos sistemas e Instituições do Ensino Superior têm vindo a induzir racionais managerialistas que têm promovido o enfraquecimento da autogovernação dos académicos, isto é, o declínio da sua influência nos processos e estruturas institucionais de tomada de decisão, o aumento da preponderância dos gestores e das lógicas gestionárias nesses processos e o incremento da representação e do papel atribuído aos representantes dos interesses externos na governação das instituições (MAGALHÃES; VEIGA, 2020; VEIGA; MAGALHÃES; AMARAL, 2015). Surge, assim, como importante pensar se e de que modo a crise provocada pela Covid-19 pode ser usada como catalisador, um reforço das transformações há décadas em curso (NEAVE, 2012) que, em última análise, podem pôr em causa valores estruturantes como os da liberdade dos académicos e da autonomia das Instituições de Ensino Superior.

\section{Envoi}

O que está em causa é, portanto, o papel das Instituições de Ensino Superior, em geral, e da universidade, em particular, na promoção de ambientes de aprendizagem que desenvolvam o potencial dos(as) estudantes para o envolvimento crítico, para a participação ativa e para a reflexão na era do digital. Entre o discurso da tecnofobia e o da celebração acrítica da digitalização e da migração para a www das experiências educativas, e cientes tanto dos interesses envolvidos neste processo como dos propósitos dos atores nele envolvidos, o desafio é reconcetualizar os processos de formação e governação das instituições, tendo em vista a sua integridade e a sua democraticidade. 
Propondo uma distância crítica diante da digitalização da educação e da sua governação, Johnston, MacNeill, Smyth (2018), sublinham que, apesar da sua crescente presença, o conceito de universidade digital é difuso e indeterminado (JOHNSTON; MACNEILL; SMYTH, 2018). Os autores assinalam o modo como as tecnologias e práticas digitais nos desafiam a repensar o posicionamento das Instituições de Ensino Superior e como é que elas podem potenciar o Ensino Superior como um bem público. Nesse sentido, o livro de que são editores traz para esta discussão a questão do curriculum digitalmente distribuído e as questões da educação aberta e da pedagogia crítica como base da experiência de aprendizagem dos(as) estudantes do Ensino Superior.

O debate sobre os caminhos e dilemas da educação superior na era do digital tem, portanto, um horizonte mais amplo do que aquele que a urgência das respostas à crise provocada pela pandemia pode fazer parecer. Esta crise, como se argumentou, tem desempenhado um papel de catalisador, de momentum, dos desenvolvimentos que, sobretudo a partir dos anos 1980, têm reconfigurado a educação superior na Europa. Trata-se, pois, de introduzir na agenda do campo da investigação da educação e das políticas educativas a discussão sobre os ambientes de aprendizagem, não restringindo o debate a uma perspetiva tecnocêntrica. Trata-se, antes, de, integrando as práticas baseadas nas tecnologias digitais, trazer os processos sociais e educativos para o centro do planeamento das mudanças organizacionais e de reforçar o carácter público da participação das instituições e da educação superior no contexto da era digital. Por outras palavras, mais do que olhar para os potenciais específicos de dadas formas de ensinar e aprender (p. ex., on-line e a distância), surge como crucial que a discussão recaia sobre o valor e a qualidade da educação e sobre como ensinar e aprender podem integrar as infraestruturas e os processos tecnológicos digitais. No trabalho já citado, Johnston, MacNeill, Smyth (2018) identificaram, precisamente, a tendência para a integração acrítica do digital nos atuais processos e estruturas dentro da universidade, em detrimento do questionamento de como os desafios da digitalização nos interpelam e como podem ser reconfigurados e reimaginados (JOHNSTON; MACNEILL; SMYTH, 2018).

Não se trata nem de construir uma nova narrativa fundadora e legitimadora da educação superior, nem de soçobrar ao amplexo da relevância económica das formações, difundida e induzida pela gramática política dominante, mas de, tendo em conta todos os discursos e vetores políticos que dominam o campo do Ensino Superior, propor que o debate político e educativo se centre na qualidade das experiências formativas proporcionadas aos(às) estudantes no contexto desse nível de educação. Este debate, por isso, reclama a reflexão sobre o que é a educação superior. Barnett (2004), posicionando-se em relação aos discursos que anunciam a dissolução da universidade, sugere que

[...] o que, porventura, está a emergir é um vislumbre de uma "universidade autêntica". A autenticidade só se torna possível precisamente quando a autenticidade é ameaçada. $\mathrm{O}$ alcançar da autenticidade é também [...] um conjunto de atos criativos nos quais novas pedagogias, novas práticas académicas e novas abordagens de investigação [são] meticulosa e dolorosamente desenvolvidas (BARNETT, 2004, p. 206).

Tanto mais que, diz o mesmo autor noutro trabalho, a dissolução da universidade não obscurece a centralidade da educação superior, porque "[...] a educação superior [...] tem de ser vista como central de uma nova forma. Não já como um veículo para a reprodução das elites do conhecimento ou para a produção de competências para o mercado de trabalho, mas como uma tarefa crucial de fornecimento de capacidade reflexiva" (BARNETT, 1997, p. 6). Assim, a educação superior é assumida como uma instituição social com o 
papel de apoiar e desenvolver a ação transformadora, e como uma importante reserva de pensamento crítico, reflexivo e alternativo. Todavia, é importante acrescentar que não bastam profissões de fé sobre a importância da educação superior e do seu papel transformador. Por exemplo, no que se refere à transformação social, como lembra Ashwin, "[...] por vezes, [...] o Ensino Superior é muito mais propenso a refletir e a reproduzir as desigualdades sociais do que a transformá-las" (ASHWIN, 2020, p. 4).

\section{Referências}

ACA [ACADEMIC COOPERATION ASSOCIATION]. The world after COVID-19 - ACA think pieces. Bruxelas: ACA, 2020.

ASHWIN, P. Transforming university education: a manifesto. Londres: Bloombury Academic, 2020.

BARNETT, R. Higher education: a critical business. Buckingham: The Society for Research into Higher Education \& Open University Press, 1997.

BARNETT, R. Epilogue: reclaiming universities from a runaway world. In: WALKER, M.; NIXON, J. Reclaiming universities from a runaway world. Buckingham: The Society for Research into Higher Education \& Open University, 2004. p. 195-208.

CHRAPLIWY, N. Postmodern education: Zoom University and the issue of presence. The Chronicle, 13 Apr. 2020. Disponível em: https://www.dukechronicle.com/article/2020/04/postmodern-education-zoomuniversity-and-the-issue-of-presence-coronavirus-covid19. Acesso em: 8 set. 2020.

COMISSÃO EUROPEIA. Comunicação da Comissão ao Parlamento Europeu, ao Conselho, ao Comité Económico e Social Europeu e ao Comité das Regiões - reforçar a identidade europeia através da educação e da cultura. Estrasburgo: Comissão Europeia, 2017. Disponível em: https://eur-lex.europa.eu/legal-content/ PT/TXT/?qid=1516193524513\&uri=CELEX:52017DC0673. Acesso em: 21 nov. 2020.

COMISSÃO EUROPEIA. Comunicação da Comissão ao Parlamento Europeu, ao Conselho, ao Comité Económico e Social Europeu e ao Comité das Regiões relativa ao Plano de Ação para a Educação Digital. Bruxelas: Comissão Europeia, 2018.

COMISSÃO EUROPEIA. Comunicação da Comissão ao Parlamento Europeu, ao Conselho, ao Comité Económico e Social Europeu e ao Comité das Regiões - Plano de Ação para a Educação Digital 2021-2027. Reconfigurar a educação e a formação para a era digital. Bruxelas: Comissão Europeia, 2020a.

COMISSÃO EUROPEIA. Communication from the Commission to the European Parliament, the Council, the European Economic and Social Committee and the Committee of the Regions. Bruxelas: Comissão Europeia, 2020b.

COWEN, R. Performativity, post-modernity and the university. Comparative Education, Abingdon, v. 32, n. 2, p. 254-258, 1996.

EVANS, S.; MCINTYRE, K. MOOCs in the humanities: can they reach underprivileged students? Convergence - The International Journal of Research into New Media Technologies, London, v. 22, n. 3, p. 313-323, 2016. 
FEVOLDEN, A.; TØMTE, C. How information and communication technology is shaping higher education. In: HUISMAN, J. et al. (orgs.). The Palgrave international handbook of higher education policy and governance. New York: Springer, 2015. p. 342-358.

FOUCAULT, M. Governmentality. In: BURCHELL, G.; GORDON, C.; MILLER, P. (orgs.). The Foucault effect, studies in governmentality. Chicago: The University of Chicago Press, 1991. p. 87-104.

GELLERT, C. Structures and functional differentiation: remarks on changing paradigms of tertiary education in Europe. In: GELLERT, C. (org.). Higher education in Europe. Londres: Jessica Kingsley, 1993. p. 234-246.

GIBBS, P.; JAMESON, J.; ELKWICK, A. Introduction. In: GIBBS, P.; JAMESON, J.; ELKWICK, A. (orgs.). Values of the university in a time of uncertainty. Cham: Springer, 2019. p. 3-13.

GIROUX, H. Neoliberalism's war on higher education. Chicago: Haymarket Books, 2014.

HOWARTH, J. P. et al. Learner motivation for MOOC registration and the role of MOOCs as a university “taster”. International Journal of Lifelong Education, Abingdon, v. 35, n. 1, p. 74-85, 2016. https://doi.org /10.1080/02601370.2015.1122667

JOHNSTON, B.; MACNEILL, S.; SMYTH, K. Conceptualising the digital university - the intersection of policy, pedagogy and practice. Cham: Palgrave Macmillan, 2018.

KATO, S.; GALÁN-MUROS, V.; WEKO, T. The emergence of alternative credentials. OECD Education Working Papers, n. 216, Paris: OECD Publishing, 2020.

LASCOUMES, P.; GALÈS, P. Introduction: understanding public policy through its instruments - from the nature of instruments to the sociology of public instrumentation. Governance, Oxford, v. 20, n. 1, p. 1-21, 2007. https://doi.org/10.1111/j.1468-0491.2007.00342.x

LONGSTAFF, E. How MOOCs can empower learners: a comparison of provider goals and user experiences. Journal of Further and Higher Education, London, v. 41, n. 3, p. 314-327, 2017. https://doi.org/10.1080/0 309877X.2015.1100715

LYOTARD, J.-F. A condição pós-moderna. Lisboa: Gradiva, 1989.

MACHEKHINA, O. N. Digitalization of education as a trend of its modernization and reforming. Revista Espacios, Caracas, v. 38, n. 40, p. 6, 2017 Disponível em: https://www.revistaespacios.com/a17v38n40/ a17v38n40p26.pdf. Acesso em: 8 set. 2020.

MAGALHÃES, A. A identidade do ensino superior: política, conhecimento e educação numa época de transição. Lisboa: Fundação Calouste Gulbenkian, 2004.

MAGALHÃES, A. A identidade do Ensino Superior: a educação superior e a universidade. Revista Lusófona de Educação, Lisboa, n. 7, p. 13-40, 2006.

MAGALHÃES, A.; VEIGA, A. What about education in higher education?” In: SMITH, L. (org.). Higher education: recent trends, emerging issues and future outlook. New York: Nova Science Publishers, 2013. p. 57-72.

MAGALHÃES, A.; VEIGA, A. Higher education institution governing boards: appointed board members. In: DAVID, M.; AMEY, M. (orgs.). The SAGE Encyclopedia of Higher Education. Thousand Oaks: Sage Publications, 2020. 
MAGALHÃES, A. et al. Governance and institutional autonomy: governing and governance in Portuguese higher education. Higher Education Policy, Amsterdam, v. 26, p. 243-262, 2013. https://doi.org/10.1057/ hep. 2012.31

NEAVE, G. The evaluative state, institutional autonomy, and re-engineering higher education in Western Europe: the prince and his pleasure. Basingstoke: Palgrave, 2012.

OECD [ORGANISATION FOR ECONOMIC CO-OPERATION AND DEVELOPMENT]. In-depth analysis of the labour market relevance and outcomes of higher education systems: analytical framework and country practices report, enhancing higher education system performance. Paris: OECD, 2017.

PETERS, M.; BARNETT, R. Introduction: the very idea of the university. In: PETERS, M.; BARNETT, R. (orgs.). The idea of the university: a reader. New York: Peter Lang. 2018. p. xii-xxxiii.

PETERS, M. et al. Reimagining the new pedagogical possibilities for universities post-Covid-19. Educational Philosophy and Theory, London, p. 1-44, 2020. https://doi.org/10.1080/00131857.2020.1777655

ROBERTS, P. Performativity, big data and higher education: the death of the professor? Beijing International Review of Education, Leiden, v. 1, n. 1, p. 73-91, 2019. https://doi.org/10.1163/25902547-00101008

ROTHBLATT, S. A historical perspective on the university's role in social development. In: DILL, D.; SPORN, B. (orgs.). Emerging patterns of social demand and university reform: through a glass darkly. Oxford: Pergamon Press, 1995. p. 20-47.

SOUSA SANTOS, B. Pela mão de Alice. Porto: Afrontamento Editores, 1994.

UNESCO [UNITED NATIONS EDUCATIONAL, SCIENTIFIC AND CULTURAL ORGANIZATION]. Dealing with obstacles to distance learning. Unesco, 20 Apr. 2020. Disponível em: https://en.unesco.org/ news/dealing-obstacles-distance-learning. Acesso em: 1 dez. 2020.

VAN DAMME, D. The resources and also the soul of the university under attack. In: Bruxelas: ACA, 2020. p. 27-39.

VEIGA, A.; MAGALHÃES, A.; AMARAL, A. From collegial governance to boardism: reconfiguring governance in higher education. In: HUISMAN, J. et al. (orgs.). The Palgrave International Handbook of Higher Education Policy and Governance. London: Palgrave Macmillan, 2015. p. 398-416.

WILLIAMSON, B. Digitizing education governance: Pearson, real-time data analytics, visualization am machine intelligence. In: WILKINS, A.; OLMEDO, A. Education governance and social theory interdisciplinary approaches to research. New York: Bloomsbury Academic, 2020. p. 21-41.

WORLD BANK. Higher education for development- an evaluation of the World Bank group's support: an independent evaluation. Washington: The World Bank, 2017.

\section{Sobre o Autor}

António M. Magalhães licenciou-se, em 1980, em Filosofia pela Universidade do Porto (Portugal), Mestre em Ciências da Educação pela Universidade do Porto (Portugal), em 1994, e Doutor em políticas do Ensino 
Superior pela Universidade de Twente (Países Baixos), em 2001. Obteve o título de Professor Agregado em 2008 e é, atualmente, Professor Catedrático da Faculdade de Psicologia e de Ciências da Educação da Universidade do Porto. É coordenador de investigação e membro da direção de Centro de Políticas do Ensino Superior. Os seus interesses de investigação focam-se na análise de políticas educativas, com ênfase nas relações entre o estado, o sistema e as Instituições de Ensino Superior, designadamente nas questões de governação e gestão, e na coordenação europeia da política educativa.

Recebido: 28 fev. 2021

Aceito: 16 jun. 2021 